\title{
Psoriasis and Glucose-6 Phosphate Dehydrogenase Deficiency: A Rare Association?
}

\author{
Irfan Tursun a, c, Gokhan Tazegul ${ }^{\mathrm{a}}$, Abdulkadir Bozbay ${ }^{\mathrm{a}}$, Seray Karagoz Ozdemir ${ }^{\mathrm{a}}$, \\ Ozan Salim ${ }^{\mathrm{b}}$, Erkan Coban ${ }^{\mathrm{a}}$
}

\begin{abstract}
Glucose-6 phosphate dehydrogenase (G6PD) is a vital enzyme for erythrocytes to be protected against oxidative stress. Its deficiency is the most common erythrocyte enzyme defect. Deficiency can cause acute or chronic hemolysis episodes. Hemolysis can be augmented by infections or drug use. Psoriasis is a complex autoimmune disorder characterized by skin involvement with inflammatory plaques. An otherwise healthy 37 years old male patient presented to internal medicine outpatient clinic with fatigue, generalized pain and skin lesions. Patient states that his sypmtoms got worse and worse after he took those medications. His past medical history was unremarkable. His family history reveals that his brother's son was recently diagnosed with G6PD deficiency. Quantitavite G6PD enzyme assay did not reveal any enzyme activity. Results were consistent with chronic hemolysis and G6PD enzyme deficiency was diagnosed as the cause. Patient's skin lesions were consulted with dermatology and he was diagnosed with psoriasis. Because he had G6PD deficiency, he was only prescribed topical treatment. The patient was relieved of all generalized body pain. Here we present a case who presented with erythematous and squamataous plaques and malaise/generalized pain, diagnosed with G6PD deficiency and psoriasis. We discuss the possible relationship between two conditions.
\end{abstract}

Keywords: Psoriasis; Glucose-6 phosphate dehydrogenase deficiency; Hemolysis

\section{Introduction}

Hexose monophosphate is the only pathway that supplies

\footnotetext{
Manuscript accepted for publication September 04, 2015

aDepartment of Internal Medicine, Akdeniz University Faculty of Medicine, Antalya, Turkey

bDivision of Hematology, Department of Internal Medicine, Akdeniz University Faculty of Medicine, Antalya, Turkey

${ }^{\mathrm{c}}$ Corresponding author: Irfan Tursun, Department of Internal Medicine, Akdeniz University Faculty of Medicine, Antalya, Turkey.

Email: tursunirfan@gmail.com
}

doi: http://dx.doi.org/10.14740/jmc2318e reduced nicotineamide adenine dinucleotide phosphate (NA$\mathrm{DPH})$ for erythrocytes and protects the cells from oxidant injury $[1,2]$. Glucose- 6 phosphate dehydrogenase (G6PD) is the first and rate-limiting step of hexose monophosphate pathway [3]. G6PD deficiency is the most common erythrocyte enzyme defect. It is genetically transmitted as X-linked recessive. Four hundred million people around the globe carry this enzyme defect [4]. Endemic areas are Africa, South Europe, Middle East and South-East Asia [5]. Prevelance of G6PD deficiency in Turkey is $0.5 \%$; however, prevelance in Cukurova region is $8.2 \%$ [6]. A study on prevelance of G6PD in West Turkey showed $0.44 \%$ severe and $6.07 \%$ mild enzyme deficiency in women and $7.24 \%$ deficiency in men [7]. Although most of the patients are asypmtomatic, some patients have hemolytic anemia episodes whereas other patients have chronic hemolysis. Hemolysis can be augmented by drugs or infections.

Psoriasis is a complex autoimmune disorder characterized by skin involvement with inflammatory plaques. Both innate and adaptive immune systems contribute to pathogenesis. Neutrophils are the predominant inflammatory cells in plaques [8]. They form localized epidermal nest of cells that are called Munro microabscesses. Here we present a case who presented with erythematous and squamataous plaques and malaise/generalized pain, diagnosed with G6PD deficiency and psoriasis. We also discuss the possible relationship between two conditions.

\section{Case Report}

An otherwise healthy 37 years old male patient presented to internal medicine outpatient clinic with fatigue, generalized pain and skin lesions. His generalized pain did not change during the daytime, and it did not improve or got worse with exercise. This pain was intermittent and he was asymptomatic between episodes. He previously went to two different medical centers, and both centers diagnosed the patient as myalgia and prescibed non-steroidal anti-inflammatory drugs and vitamin C. Patient states that his sypmtoms got worse and worse after he took those medications. His past medical history was unremarkable. His family history reveals that his brother's son was recently diagnosed with G6PD deficiency.

His physical examination was as follows: body tempera- 


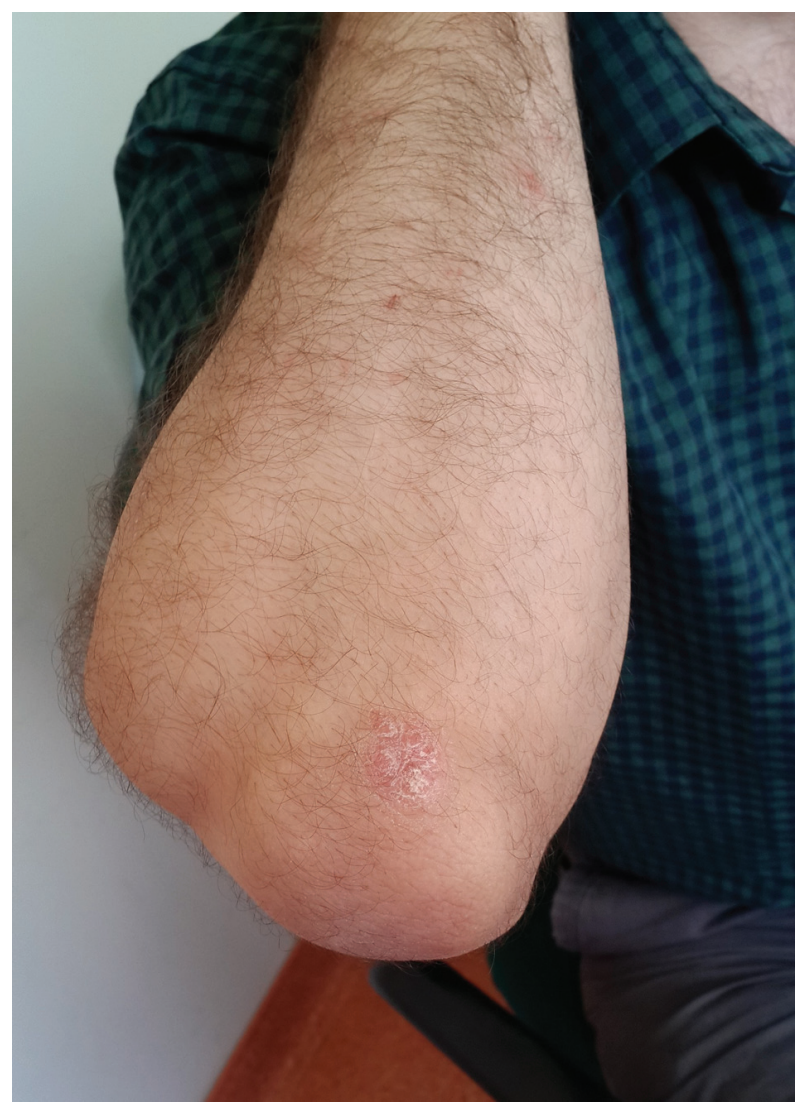

Figure 1. Patient's right elbow.

ture: $36.7^{\circ} \mathrm{C}$, blood pressure: $130 / 60 \mathrm{~mm} \mathrm{Hg}$ with 86 beats $/ \mathrm{min}$. Skin examination revealed erythematous and squamataous plaque formations on his elbows, torso and scalp. Peripheral blood smear did show polychromasia but blister cells were not seen. Patient states he did not see a doctor regarding these skin lesions. His lesions can be seen in Figures 1-3.

Patient's labaratory results are presented in Table 1. Quantitavite G6PD enzyme assay did not reveal any enzyme activity. Results were consistent with chronic hemolysis and G6PD enzyme deficiency was diagnosed as the cause. Patient was informed of diet regulations and he should not use drugs. He was also prescribed with folate and vitamin E.

Patient's skin lesions were consulted with dermatology and he was diagnosed with psoriasis. Because he had G6PD deficiency, he was only prescribed topical treatment. The patient was relieved of all generalized body pain.

\section{Discussion}

G6PD deficiency is the most common enzyme defect that causes hemolytic anemia. It is transmitted by an X-recessive fashion. Males can be either normal or hemizygous, and females can be normal, heterozygous or homozygous. World Health Organization classifies G6PD deficiency into five variant classes. Class 1 variant has severe enzyme deficiency $(<$ $10 \%$ ) and chronic hemolytic anemia, class 2 variant has severe

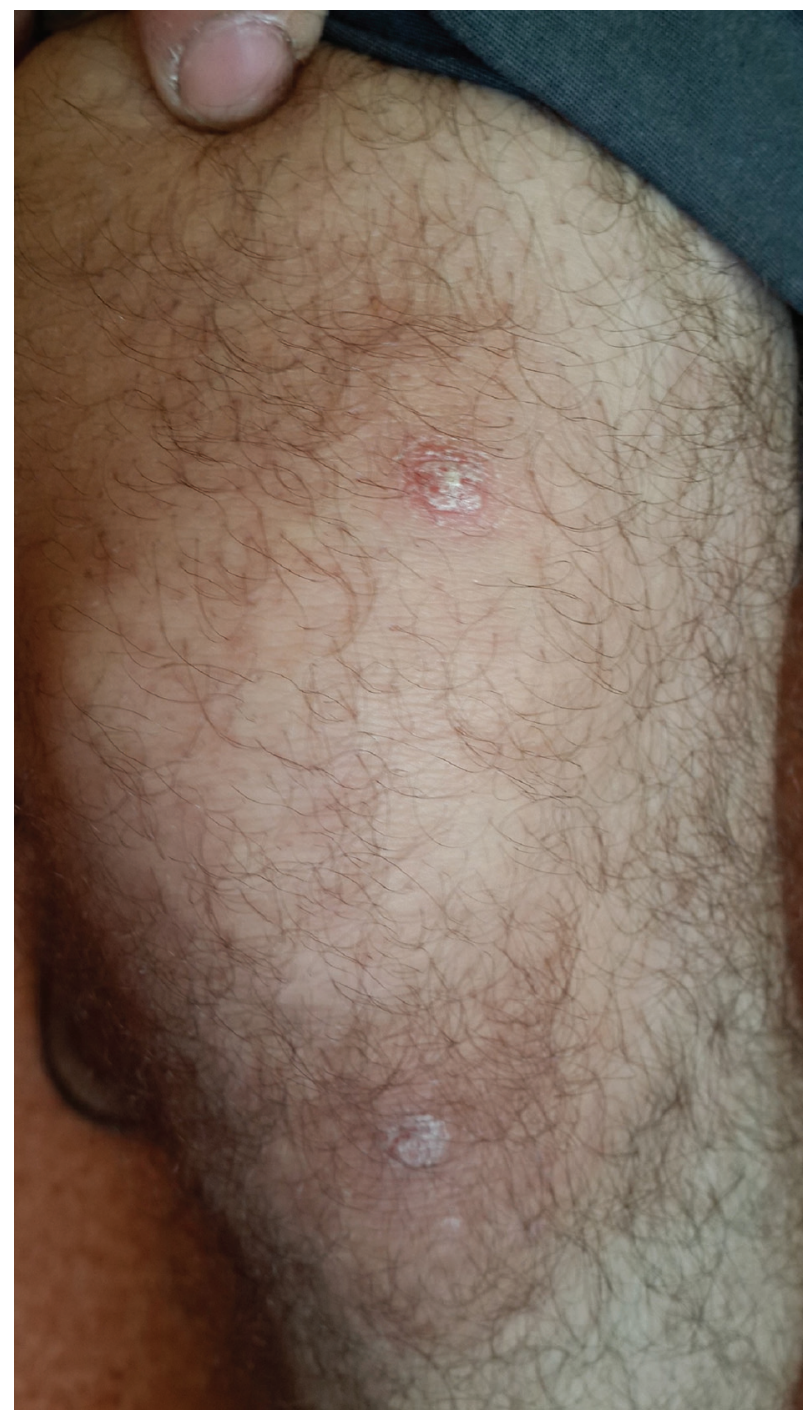

Figure 2. Patient's right knee.

enzyme deficiency and intermittant hemolysis, class 3 variant has moderate enzyme deficiency (10-60\%) and intermittant hemolysis caused by drugs and/or infections, class 4 variant is normal and class 5 variant has increased enzyme activity $[1,9]$. Our patient had class 1 variant enzyme with severe deficiency.

Drug choice for treatment of comorbities in patients with G6PD is of importance. Primaquine, sulfamethoxazole, dapsone, nitrofurantoin, nalidixic acid, and co-trimoxazole are some of the drugs that have definite association with hemolysis. Use of chloroquine, sulfasalazine, mesalazine, acetylsalicylic acid, ciprofloxacin, ascorbic acid and vitamin $\mathrm{K}$ analogues, quinine, paracetamol, aminosalicylic acid, probenecid, dimercaprol, nifedipine, sodium nitroprusside, metoclopromide, methylene blue, phenylenediamine (hair dye), napthalene (moth balls) and henna (dye) have possible association with hemolytic episodes $[4,10]$. There are no specific papers on drugs used in psoriasis that may have caused hemolysis in patients with G6PD deficiency. Our patient had used non-ste- 


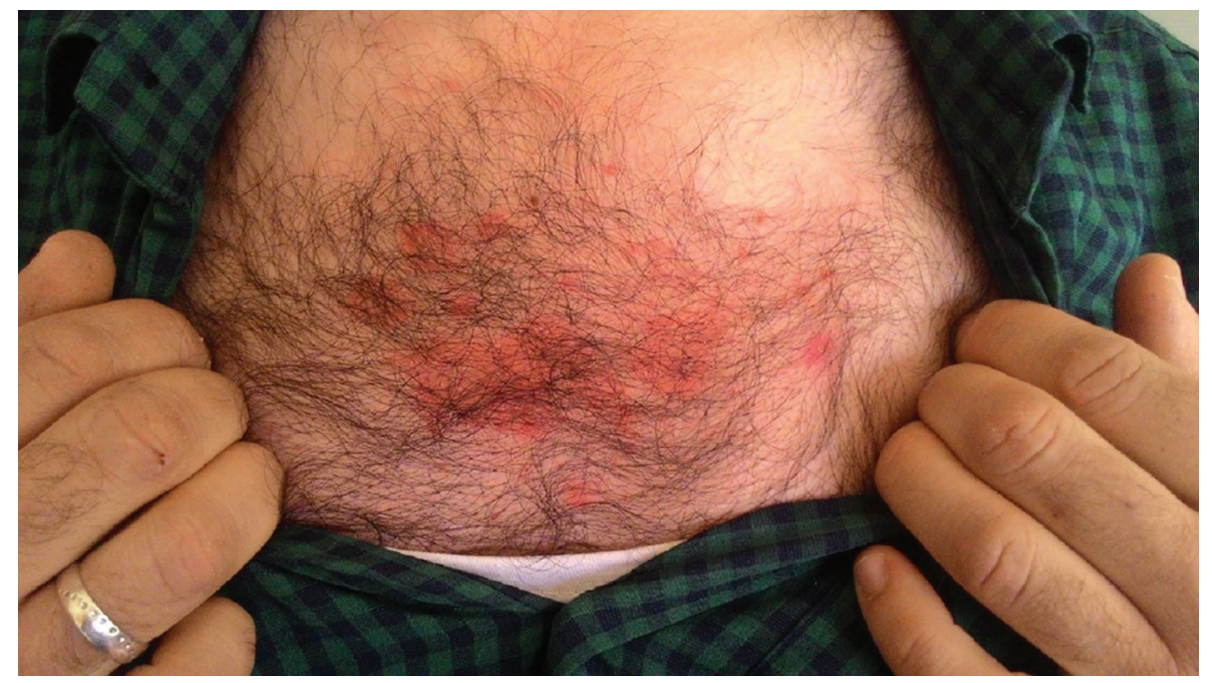

Figure 3. Patient's chest.

roidal anti-inflammatory drugs and excessive doses of vitamin $\mathrm{C}$ which may have triggered hemolysis.

Patients with G6PD deficiency may present themselves with generalized body pain as well as back pain. Patients may also report increased symptoms after using specific drugs such as ascorbic acid or non-steroidal anti inflammatory drugs. Choosing drugs for comorbidites in patients with G6PD deficiency is important and patients need to be followed during their treatment for hemolysis. There are no reported cases of psoriasis along with G6PD deficiency to the author's knowledge and this patient is believed to have these two conditions coincidentally.

However, deficiency of G6PD was found to be related to other autoimmune diseases. A reseach on Sudanese vitiligo pa- tients revealed an excess deficiency of G6PD compared to the controls [11]. Type 1 diabetic patients with G6PD deficiency also suffer from accelerated microvascular complications such as retinopathy [12]. A study on Sardinian population revealed conflicting results, stating that G6PD deficiency showed a trend for protection against proliferative retinopathy [13]. Another coincidental case of G6PD deficiency with celiac disease was also reported [14].

G6PD enzyme is regulated with the same gene in leukocytes and platelets. When defective, there is also decreased enzyme levels for those cells as well, but they rarely cause clinical manifestations $[15,16]$. Heavy enzyme defects (less than $5 \%$ ) may cause decreased respiratory burst activity of granulocytes which may present itself as chronic granulatmatous

Table 1. Patient's Laboratory Results

\begin{tabular}{lll}
\hline Parameters & Result & Reference range \\
\hline Hemoglobin & $14 \mathrm{~g} / \mathrm{dL}$ & $12-16 \mathrm{~g} / \mathrm{dL}$ \\
Hematocrit & $45 \%$ & $35-52 \%$ \\
Leukocytes & $6,700 / \mathrm{mm}^{3}$ & $4,800-10,800 / \mathrm{mm}^{3}$ \\
Corrected reticulocyte count & $4 \%$ & $0.5-1.5 \%$ \\
Mean corpuscular volume (MCV) & $92 \mathrm{fL}$ & $80-102 \mathrm{fL}$ \\
Platelets & $254,000 / \mathrm{mm}^{3}$ & $150,000-450,000 / \mathrm{mm}^{3}$ \\
Direct Coombs & Negative & Negative \\
Indirect Coombs & Negative & Negative \\
C-reactive protein (CRP) & $0.13 \mathrm{mg} / \mathrm{dL}$ & $0-0.5 \mathrm{mg} / \mathrm{dL}$ \\
Sedimentation (1 h) & $2 \mathrm{~mm} / \mathrm{h}$ & $<10 \mathrm{~mm} / \mathrm{h}$ \\
Aspartate aminotransferase (AST) & $29 \mathrm{U} / \mathrm{L}$ & $0-40 \mathrm{U} / \mathrm{L}$ \\
Lactate dehydrogenase (LDH) & $390 \mathrm{U} / \mathrm{L}$ & $135-214 \mathrm{U} / \mathrm{L}$ \\
Total bilirubin & $1.63 \mathrm{mg} / \mathrm{dL}$ & $0.1-1.2 \mathrm{mg} / \mathrm{dL}$ \\
Indirect bilirubin & $1.32 \mathrm{mg} / \mathrm{dL}$ & $0.2-0.7 \mathrm{mg} / \mathrm{dL}$ \\
Anti-nuclear antigen (ANA) & Negative & Negative \\
Glucose-6 phosphate dehydrogenase activity (quantitative) & No activity & $4.1-10.1 \mathrm{U} / \mathrm{gHb}$ \\
\hline
\end{tabular}


infections $[17,18]$. A decrease in G6PD also occurs when the enzyme is deficient in the skin and favizm can be diagnosed from a skin biopsy [19].

It was also previously suggested that in regions with high frequency of G6PD deficiency psoriasis was uncommon [19]. It was proven that in patient's skin involved with psoriasis strong G6PD activity occurred focally in superficial cells of malphighian layer, stratum granulosum and the overlying parakeratotic layer. Uninvolved skin of psoriatic patients and healthy control patients had confined G6PD activity only to pilosebaceous unit [20]. Another paper on in vitro activity of anti-G6PD agents in psoriatic therapeutics stated that most active inhibitor was methotrexate followed by cGMP [21]. Erythrocyte kinetics also change with psoriasis: membrane fluidity decreases and cytoskeleton is impaired. This caused reduced propensity to hemolysis [22]. Although it is believed that this patient has these two diseases coincidentally, psoriasis and G6PD deficiency might overlap with more serious or more mild clinical tables. However, it cannot be concluded from this case.

\section{Conflict of Interest}

We have no conflict of interest to declare.

\section{Sources of Support}

None.

\section{Abbreviations}

G6PD: glucose-6 phosphate dehydrogenase; NADP: nicotineamide adenine dinucleotide phosphate; NADPH: reduced nicotineamide adenine dinucleotide phosphate

\section{References}

1. Siems WG, Sommerburg O, Grune T. Erythrocyte free radical and energy metabolism. Clin Nephrol. 2000;53(Suppl 1):9-17.

2. Mehta A, Mason PJ, Vulliamy TJ. Glucose-6 phosphate dehydrogenase deficiency. Bailliers Best Pract Res Clin Haematol Mar. 2000;13:21-38.

3. Beutler E. The molecular biology of enzymes of erythrocyte metabolism. In: The Molecular Basis of Blood Disease, Stamatoyannopoulos G, Nienhus AW, Majerus PW, et al. (Eds), WB Saunders, Philadelphia 1993.

4. Brandt O, Rieger A, Geusau A, Stingl G. Peas, beans, and the Pythagorean theorem - the relevance of glucose6-phosphate dehydrogenase deficiency in dermatology. J Dtsch Dermatol Ges. 2008;6(7):534-539.

5. Luzzatto L. Glucose 6-phosphate dehydrogenase deficiency: from genotype to phenotype. Haematologica. 2006;91(10):1303-1306.
6. Salvati AM, Maffi D, Caprari P, Pasquino MT, Caforio MP, Tarzia A. [Glucose-6-phosphate dehydrogenase deficiency and hereditary hemolytic anemia]. Ann Ist Super Sanita. 1999;35(2):193-203.

7. Turan Y. Prevalence of erythrocyte glucose-6-phosphate dehydrogenase (G6PD) deficiency in the population of western Turkey. Arch Med Res. 2006;37(7):880-882.

8. van de Kerkhof PC, Lammers AM. Intraepidermal accumulation of polymorphonuclear leukocytes in chronic stable plaque psoriasis. Dermatologica. 1987;174(5):224227.

9. Fiorelli G, Martinez di Montemuros F, Cappellini MD. Chronic non-spherocytic haemolytic disorders associated with glucose-6-phosphate dehydrogenase variants. Baillieres Best Pract Res Clin Haematol. 2000;13(1):39-55.

10. Cappellini MD, Fiorelli G. Glucose-6-phosphate dehydrogenase deficiency. Lancet. 2008;371(9606):64-74.

11. Saha N, Ahmed MA, Wasfi AI, El Munshid HA. Distribution of serum proteins, red cell enzymes and haemoglobins in vitiligo. Hum Hered. 1982;32(1):46-48.

12. Cappai G, Songini M, Doria A, Cavallerano JD, Lorenzi M. Increased prevalence of proliferative retinopathy in patients with type 1 diabetes who are deficient in glucose-6-phosphate dehydrogenase. Diabetologia. 2011;54(6):1539-1542.

13. Pinna A, Contini EL, Carru C, Solinas G. Glucose6-phosphate dehydrogenase deficiency and diabetes mellitus with severe retinal complications in a Sardinian population, Italy. Int J Med Sci. 2013;10(13):1907-1913.

14. Hosnut FO, Canan O, Ozcay F, Ozbek N. Awareness of glucose-6 phosphate-dehydrogenase deficiency in celiac disease. Acta Paediatr. 2010;99(5):786-788.

15. Miller DR, Wollman MR. A new variant of glucose6-phosphate dehydrogenase deficiency hereditary hemolytic anemia, G6PD Cornell: erythrocyte, leukocyte, and platelet studies. Blood. 1974;44(3):323-331.

16. Schiliro G, Russo A, Mauro L, Pizzarelli G, Marino S. Leukocyte function and characterization of leukocyte glucose-6-phosphate dehydrogenase in Sicilian mutants. Pediatr Res. 1976;10(8):739-742.

17. Vives Corrons JL, Feliu E, Pujades MA, Cardellach F, Rozman C, Carreras A, Jou JM, et al. Severe-glucose6-phosphate dehydrogenase (G6PD) deficiency associated with chronic hemolytic anemia, granulocyte dysfunction, and increased susceptibility to infections: description of a new molecular variant (G6PD Barcelona). Blood. 1982;59(2):428-434.

18. van Bruggen R, Bautista JM, Petropoulou T, de Boer M, van Zwieten R, Gomez-Gallego F, Belohradsky BH, et al. Deletion of leucine 61 in glucose-6-phosphate dehydrogenase leads to chronic nonspherocytic anemia, granulocyte dysfunction, and increased susceptibility to infections. Blood. 2002;100(3):1026-1030.

19. Jacyk WK. Erythrocyte glucose-6-phosphate dehydrogenase in lichen planus. Arch Dermatol Res. 1978;261(3):331-332.

20. Jones WA, Helwig EB, Harman LE. Oxidative Enzyme Activity in the Skin of Patients with Psoriasis: A Histochemical Study. J Invest Dermatol. 1965;44:189-195. 
21. Cotton DW, van Rossum E. Psoriatic therapeutics and glucose-6-phosphate dehydrogenase. Arch Dermatol Forsch. 1975;252(2):147-149.
22. Gornicki A. Changes in erythrocyte microrheology in patients with psoriasis. Clin Exp Dermatol. 2004;29(1):6770. 